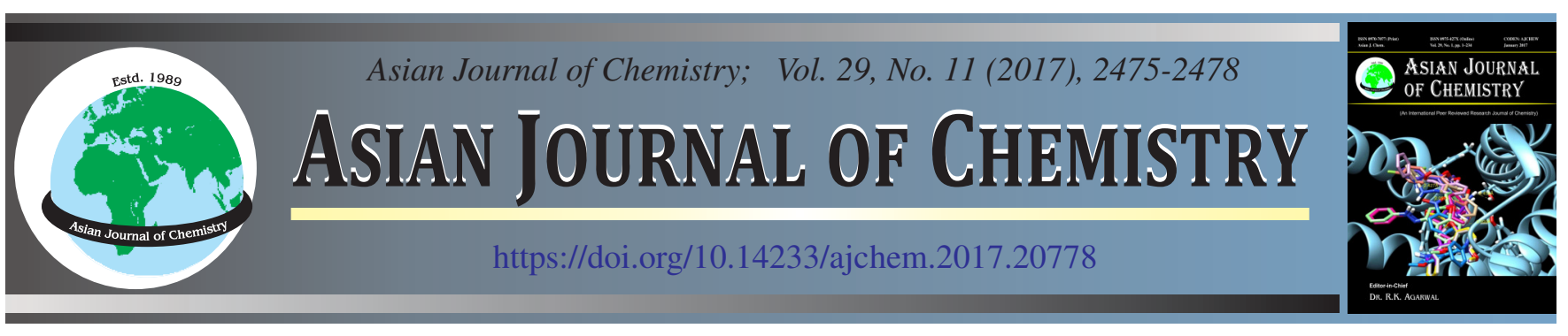

\title{
N-S Codoped Cerium-Cobalt Oxide Bimetal Nanoparticles Catalyzed Photodegradation of Brilliant Green and Fast Green
}

\author{
Jyoti ShARMA and K.L. AmETA*
}

Department of Chemistry, Mody University of Science and Technology, Lakshmangarh-332 311, India

*Corresponding author: E-mail: klameta77@ hotmail.com

Received: 12 May 2017;

Accepted: 17 August 2017;

Published online: 29 September 2017;

AJC-18575

\begin{abstract}
Cerium-cobalt oxide bimetal nanoparticles were synthesized using wet precipitation method and characterized by X-ray diffraction (XRD) and scanning electron microscopy (SEM). The photocatalyzed degradation of brilliant green and fast green dyes were studied using $\mathrm{CeCoO}_{3}$ bimetallic nanoparticles spectrophotometrically. Photocatalytic activity has been tested in the reaction of these dyes under visible irradiation. It was revealed that doping enhanced the photocatalytic activity at low doping levels but reduced the activity at high doping levels. Various parameters like amount of semiconductor, $\mathrm{pH}$, light intensity, dye concentration, \% of dopant were also studied. The rate of reaction followed pseudo-first order kinetics.
\end{abstract}

Keywords: Photodegradation, Cerium-Cobalt oxide, Nanoparticles, Brilliant green, Fast green.

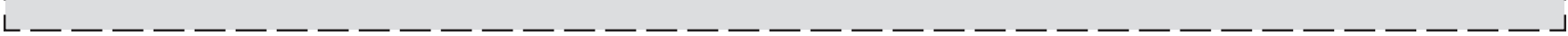

\section{INTRODUCTION}

Discharge of effluents into the water bodies causes severe pollution of surface as well as ground water. Addition of water containing various dyes leads to loss of biodiversity in water bodies and it also leads to increased toxicity level of water studied by Khetan et al. [1,2]. The various methods for removal of synthetic dyes such as adsorption, microbiological de-coloration, activated sludge, pure cultures and microbe consortiums exist was suggested by Forgacs et al. [3]. Tang et al. concluded that among various methods photo degradation occupies a prominent method in dye removal. Generally, oxides and sulphides are being used as photocatalyst [4-6]. Photocatalytic studies on the degradation of methylene blue using $\mathrm{TiO}_{2}$ and $\mathrm{ZnO}$ as photocatalyst under UV radiation was studied by Mohababsi and co-workers [7]. Ullah et al. explored Fe/ZnO/ $\mathrm{SiO}_{2}$ as catalyst and found $100 \%$ degradation of methylene blue at $\mathrm{pH} 4$, with in $30 \mathrm{~min}$ and $0.075 \mathrm{~g} / \mathrm{L}$ catalyst loading [8]. Use of $\mathrm{ZnO}$ nanoparticles as photocatalyst for the treatment of trypan blue and hexavalent chromium with solar energy was studied by Banerjee et al. [9]. Saharan et al. reported photocatalytic degradation of Victoria blue $\mathrm{R}$ and Fast green FCF dyes using $\mathrm{Y}_{-}-\mathrm{Fe}_{2} \mathrm{O}_{3}$ and $\mathrm{Fe}_{3} \mathrm{O}_{4}$ nanoparticles [10]. Simultaneous adsorption of Congo red, Phloxine, fast green onto $\mathrm{CuS} / \mathrm{ZnS}$ nanocomposites which were loaded on activated carbon and their reaction was studied by Pooralhossini et al. spectrophotometrically [11]. Ameta et al. reported photodegradation of malachite green using cerium cadmium oxide as nanoparticles [12]. Photocatalytic activity on methylene blue of N-S Codoped $\mathrm{TiO}_{2}$ nanotubes array films showed a better photocatalytic activity than undoped sample according to Goutian et al. [13]. Ag-doped $\mathrm{TiO}_{2}$ photocatalyst for the degradation of tartrazine and chloramphenicol under UV light irradiation was studied by Dawery and observed that under similar condition photodegradation of tartrazine was faster than that of chloramphenicol [14]. Mo doped $\mathrm{ZnO}$ was synthesized and studied as photocatalyst in the bleaching of eosin yellow dye by Vaya and co-workers [15]. Tolia et al. synthesized Mn doped $\mathrm{ZnS}$ and undoped $\mathrm{ZnS}$ using mechanochemical method for the degradation of malachite green [16]. Ahmed et al. reported heterogeneous photocatalytic water purification process which has gained wide attention due to its effectiveness in degradation and mineralization of organic compounds and utilization of UV and visible light spectrum [17]. Comparative study of photo degradation of dyes using commercial and synthesized $\mathrm{TiO}_{2}$ photocatalyst was successfullystudied by Mohammad and co-workers [18]. In continuation of our research programme, we herein report the photocatalytic degradation of fast green and brilliant green using N-S codoped ceriumcobalt oxide bimetal nanocomposites as photocatalysts.

\section{EXPERIMENTAL}

Synthesis of cerium-cobalt oxide: Aqueous solutions of $0.1 \mathrm{M}$ of both $\mathrm{Ce}\left(\mathrm{NO}_{3}\right)_{3} \cdot 6 \mathrm{H}_{2} \mathrm{O}$ and $\mathrm{Co}\left(\mathrm{NO}_{3}\right)_{2} \cdot 6 \mathrm{H}_{2} \mathrm{O}$ was mixed with continuous stirring. The $\mathrm{pH}$ of the reaction mixture was adjusted at $11.0 \mathrm{pH}$ by adding an aqueous solution of $1 \mathrm{M}$ 
$\mathrm{NaOH}$ drop-wise to the reaction mixture. At this $\mathrm{pH}$ complete precipitation was noticed. After stirring of $4 \mathrm{~h}$, reaction mixture was filtered and washed several times with cold water.The residue was dried at $110^{\circ} \mathrm{C}$ in an oven. The dried residue was grounded with acetone using pestle and mortar.In muffle furnace solid powder is calcined at $500{ }^{\circ} \mathrm{C}$ for $4 \mathrm{~h}$ under static air.

Synthesis of N-S codoped cerium-cobalt oxide: Variable amount of cerium cobalt oxide $(0.5,1.0,2.0$ and $2.5 \mathrm{~g}), 50 \mathrm{~mL}$ of iso-propanol and $0.5,1.0,2.0$ and $2.5 \mathrm{~g}$ of thiouraea in 100 $\mathrm{mL}$ of doubly distilled water was taken in 5 different conical flasks respectively. Thiourea was used as source of doping $\mathrm{N}-\mathrm{S}$ on nanoparticles. The solution was vigorously stirred at very high speed for $5 \mathrm{~h}$ and was kept overnight at room temperature. Then filtering the mixture and washing with cold distilled water was done. After that filtrate was dried for $4 \mathrm{~h}$ at $80{ }^{\circ} \mathrm{C}$ and calcined at $400{ }^{\circ} \mathrm{C}$ for $4 \mathrm{~h}$ to get $\mathrm{N}$, S-codoped cerium cobalt nitrate oxide.

A stock solution $\left(1 \times 10^{-3} \mathrm{M}\right)$ of brilliant green dye and of fast green dye was prepared in doubly distilled water. The stock solution was further diluted as per requirement. The photocatalytic degradation of dyes were observed by taking dye solution of $2.12 \times 10^{-5} \mathrm{~mol} / \mathrm{L}$ and $0.02 \mathrm{~g} \mathrm{CeCoO}_{3}$ for brilliant green and $1.40 \times 10^{-5} \mathrm{~mol} / \mathrm{L}$ and $0.04 \mathrm{~g} \mathrm{CeCoO}_{3}$ for fast green. Irradiation was carried out by keeping complete set up exposed to a $200 \mathrm{~W}$ tungsten lamp (Philips). The intensity of light was measured with solarimeter (SM CEL 201). The $\mathrm{pH}$ of the solution was measured by the digital $\mathrm{pH}$ meter (Systronics Model 335). The desired $\mathrm{pH}$ of the solution was adjusted by the addition of previously standardized sulphuric acid and sodium hydroxide solutions. The optical density (OD) was measured spectrophotometrically (systronics Model 106). The progress of reaction was observed by observing optical density at regular interval of time.

Photocatalytic activity of $\mathrm{N}-\mathrm{S}$ codoped $\mathrm{CeCoO}_{3}$ : In a $50 \mathrm{~mL}$ beaker, $30 \mathrm{~mL}$ of dye solution with photocatalyst was taken. The optical density was measured at regular intervals of time at $620 \mathrm{~nm}$ for bothfast green and brilliant green. The $\mathrm{pH}$ of reaction mixtures were kept at 8.5 and 9.0 for fast green and brilliant green respectively for these solutions and were exposed to $200 \mathrm{~W}$ tungsten lamp. The decrease in absorbance of both the dye solutions was observed with increasing time of exposure. Decrease in optical density indicates that dyes were degraded on irradiation. The plot of $1+\log$ OD against time was found linear and follows pseudo first order kinetics for both the dyes (Fig. 1). The rate constant was calculated by using the expression $\mathrm{k}=2.303 \times$ slope. The rate constant for these reactions at optimum conditions were determined as $\mathrm{k}=$ $3.86 \times 10^{-4}$ (Brilliant green) and $\mathrm{k}=5.12 \times 10^{-4}$ (fast green)

\section{RESULTS AND DISCUSSION}

The prepared nanoparticle was characterized by $\mathrm{X}$ ray diffraction and scanning electron microscopy. Fig. 2 presents the X-ray diffraction patterns of $\mathrm{CeCoO}_{3}$. The graph has been plotted between intensity (cycles per second) and $2 \theta$ values (in degrees), for general consideration $2 \theta$ value ranges from $20-80^{\circ}$.

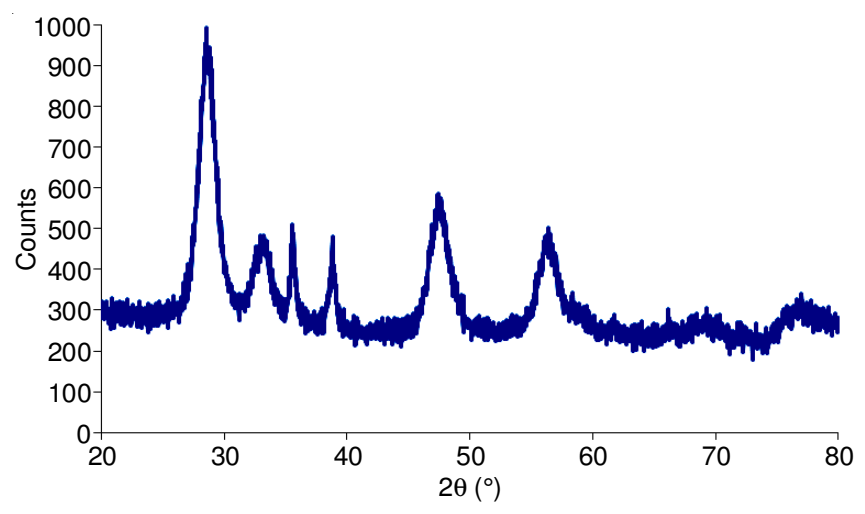

Fig. 2. X-ray diffraction of $\mathrm{CeCoO}_{3}$

The number weighted particle size was found to be comparable with the volume-weighted mean size obtained from the broadening of the X-ray diffraction lines (Scherer equation: $\mathrm{D}=\mathrm{K} \lambda / \mathrm{B} \cos \theta)$.

Scanning electron microscope (SEM): SEM has been used to identify and for morphological characterization of

\begin{tabular}{|c|c|c|c|c|c|}
\hline \multicolumn{3}{|c|}{$\begin{array}{l}\text { Brilliant green } \\
{[\text { Brilliant green }]=2.12 \times 10^{-5}} \\
{\left[\mathrm{CeCoO}_{3}\right]=0.02 \mathrm{~g}} \\
\mathrm{pH}=9.0 \\
\text { Dopant } \%=1.5 \% \\
\text { Light intensity }=50.0 \mathrm{mWcm}^{-2}\end{array}$} & \multicolumn{3}{|c|}{$\begin{array}{l}\text { Fast green } \\
{[\text { Fast green }]=1.40 \times 10^{-5}} \\
{\left[\mathrm{CeCoO}_{3}\right]=0.04 \mathrm{~g}} \\
\mathrm{pH}=8.5 \\
\text { Dopant } \%=2 \% \\
\text { Light intensity }=50.0 \mathrm{mWcm}^{-2}\end{array}$} \\
\hline $\begin{array}{l}\text { Time } \\
(\min )\end{array}$ & $\begin{array}{l}\text { Brilliant } \\
\text { green } \\
\text { (OD) }\end{array}$ & $\begin{array}{c}\text { Brilliant green } \\
(1+\log \text { OD })\end{array}$ & $\begin{array}{l}\text { Time } \\
(\min )\end{array}$ & $\begin{array}{l}\text { Fast } \\
\text { green } \\
\text { (OD) }\end{array}$ & $\begin{array}{l}\text { Fast green } \\
(1+\log \text { OD })\end{array}$ \\
\hline 0 & 0.941 & 0.974 & 0 & 0.880 & 0.944 \\
\hline 10 & 0.797 & 0.901 & 10 & 0.721 & 0.858 \\
\hline 20 & 0.651 & 0.814 & 20 & 0.495 & 0.695 \\
\hline 30 & 0.545 & 0.736 & 30 & 0.389 & 0.590 \\
\hline 40 & 0.41 & 0.613 & 40 & 0.310 & 0.491 \\
\hline 50 & 0.345 & 0.538 & 50 & 0.214 & 0.330 \\
\hline 60 & 0.275 & 0.439 & 60 & 0.140 & 0.146 \\
\hline 70 & 0.186 & 0.270 & 70 & 0.102 & 0.009 \\
\hline \multicolumn{3}{|c|}{$\mathrm{k}=3.86 \times 10^{-4} \mathrm{sec}^{-1}$} & \multicolumn{3}{|c|}{$\mathrm{k}=5.12 \times 10^{-4} \mathrm{sec}^{-1}$} \\
\hline
\end{tabular}

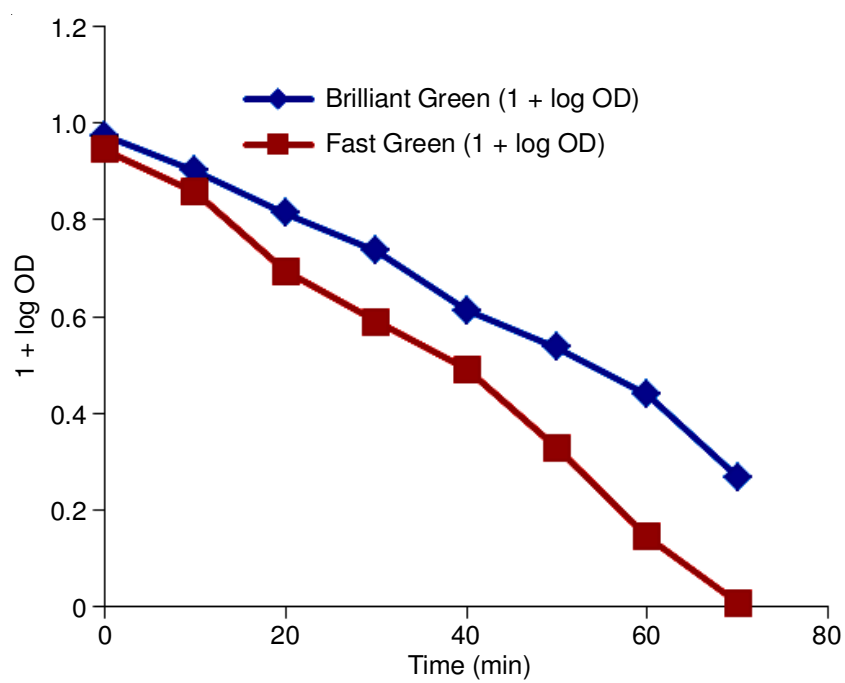

Fig. 1. A typical run 
nano-crystalline $\mathrm{CeCoO}_{3}$. The surface and morphological studies were carried out using scanning electron microscope Jeol JSM-6390 LV with EDS (INCA) as shown in Fig. 3 (Pure $\mathrm{CeCoO}_{3}$ ) and Fig. 4 (N,S-codoped). It is clear from the image that the size of a cluster was $5 \mu \mathrm{m}$ at $4500 \mathrm{X}$ magnification for pure sample and for doped sample it was $10 \mu \mathrm{m}$ at $1500 \mathrm{X}$ in its crystalline form.

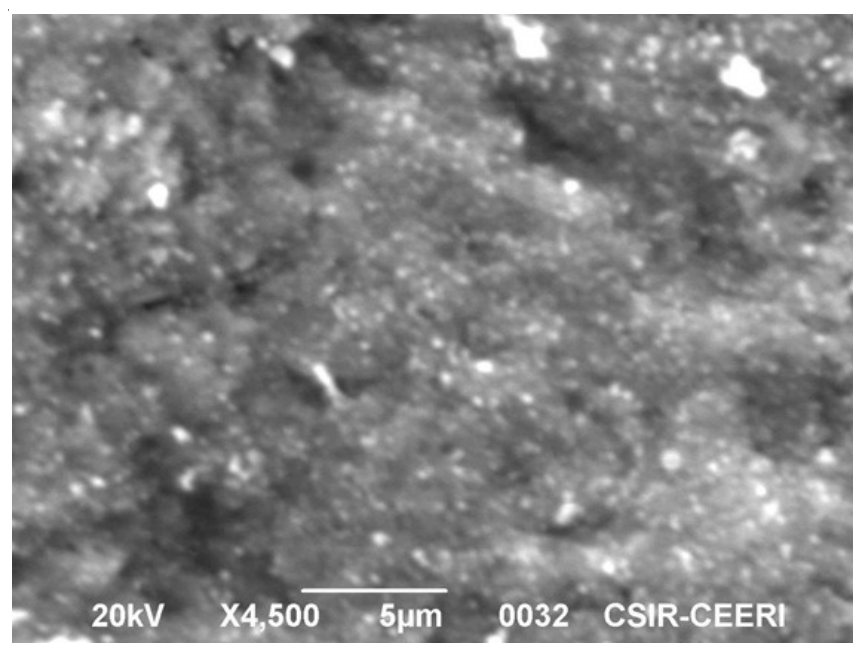

Fig. 3. SEM of pure $\mathrm{CeCoO}_{3}$

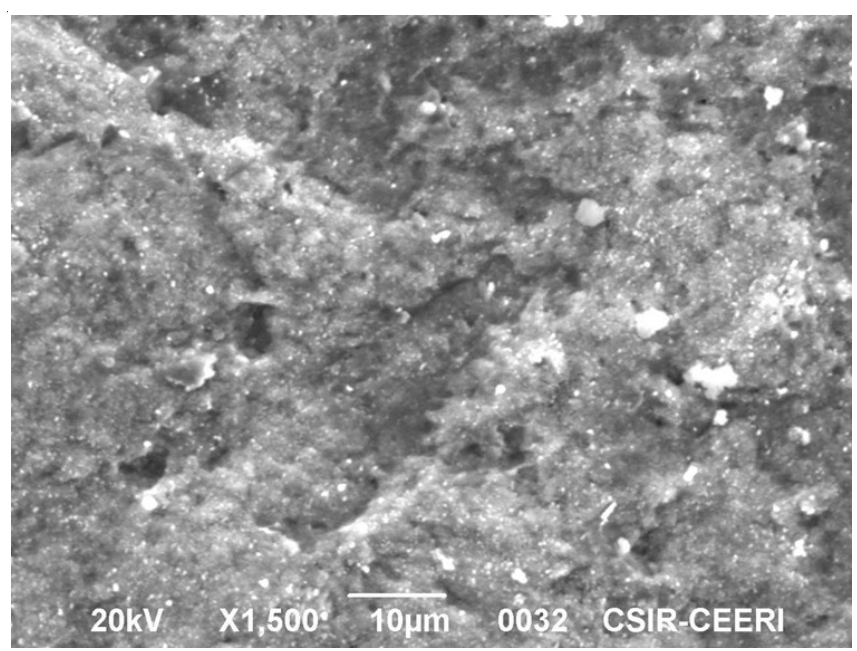

Fig. 4. SEM of N,S-codoped $\mathrm{CeCoO}_{3}$

Effect of pH: The effect of $\mathrm{pH}$ on photocatalytic degradation was investigated. The results are reported in (Table-1).

It is clear from the data that the rate of degradation of fast green dye increases with increasing $\mathrm{pH}$ up to 8.5 and above this value of $\mathrm{pH}$; there is a decrease in the rate of photocatalysis. It may because of negative charge on semiconductor and neutral form of dye, but dye is electron rich and due to presence of lone pairs on two nitrogen atoms which results in repulsion between dye molecule and negatively charged surface of the semiconductor, which in turn results in decrease in the rate of reaction. In brilliant green dye rate of degradation increased upto $\mathrm{pH} 9.0$ and after that there is decrease in rate of degradation as the $\mathrm{OH}$ radicals are responsible for the oxidative degradation of dyes. With increase in $\mathrm{pH}$ more- $\mathrm{OH}$ ions are available and these are adsorbed on the surface of the semiconductor making it negatively charged so that the approach

\begin{tabular}{|c|c|c|c|}
\hline \multicolumn{4}{|c|}{$\begin{array}{c}\text { TABLE-1 } \\
\text { EFFECT OF pH }\end{array}$} \\
\hline \multicolumn{2}{|c|}{$\begin{array}{l}\text { Brilliant green } \\
{[\text { Brilliant green }]=2.12 \times 10^{-5}} \\
{\left[\mathrm{CeCoO}_{3}\right]=0.02 \mathrm{~g}} \\
\text { Dopant } \%=1.5 \% \\
\text { Light intensity }=50.0 \mathrm{mWcm}^{-2}\end{array}$} & \multicolumn{2}{|c|}{$\begin{array}{l}\text { Fast green } \\
{[\text { Fast green }]=1.40 \times 10^{-5}} \\
{\left[\mathrm{CeCoO}_{3}\right]=0.04 \mathrm{~g}} \\
\text { Dopant } \%=2 \% \\
\text { Light intensity }=50.0 \mathrm{mWcm}^{-2}\end{array}$} \\
\hline $\mathrm{pH}$ & $\mathrm{k} \times 10^{4} \mathrm{~s}^{-1}$ & $\mathrm{pH}$ & $\mathrm{k} \times 10^{4} \mathrm{~s}^{-1}$ \\
\hline 5.0 & 1.85 & 5.0 & 1.20 \\
\hline 5.5 & 1.92 & 5.5 & 1.24 \\
\hline 6.0 & 2.30 & 6.0 & 1.75 \\
\hline 6.5 & 2.65 & 6.5 & 2.54 \\
\hline 7.0 & 2.89 & 7.0 & 3.72 \\
\hline 7.5 & 3.15 & 7.5 & 4.10 \\
\hline 8.0 & 3.45 & 8.0 & 4.65 \\
\hline 8.5 & 3.78 & 8.5 & 5.12 \\
\hline 9.0 & 3.86 & 9.0 & 4.94 \\
\hline
\end{tabular}

of cationic form of brilliant green will have a force of attraction towards surface of semiconductor. With further increase, there will be no attraction between negatively charged surface of the semiconductor and neutral form of the dye. This leads to a decrease in the rate of degradation.

Effect of concentration of dyes: The concentration of dyes was varied from $1.00 \times 10^{-5} \mathrm{M}$ to $1.90 \times 10^{-5} \mathrm{M}$ and $1.78 \times$ $10^{-5} \mathrm{M}$ to $2.32 \times 10^{-5} \mathrm{M}$ for fast green and brilliant green respectively. The results are shown in Table- 2 .

\begin{tabular}{|c|c|c|c|}
\hline \multicolumn{4}{|c|}{$\begin{array}{c}\text { TABLE-2 } \\
\text { EFFECTS OF CONCENTRATION OF DYES }\end{array}$} \\
\hline \multicolumn{2}{|c|}{$\begin{array}{l}\text { Brilliant green } \\
{\left[\mathrm{CeCoO}_{3}\right]=0.02 \mathrm{~g}} \\
\text { Dopant } \%=1.5 \% \\
\mathrm{pH}=9.0 \\
\text { Light intensity }=50.0 \mathrm{mWcm}^{-2}\end{array}$} & \multicolumn{2}{|c|}{$\begin{array}{l}\text { Fast green } \\
{\left[\mathrm{CeCoO}_{3}\right]=0.04 \mathrm{~g}} \\
\text { Dopant } \%=2 \% \\
\mathrm{pH}=8.5 \\
\text { Light intensity }=50.0 \mathrm{mWcm}^{-2}\end{array}$} \\
\hline $\begin{array}{c}\text { Brilliant green } \\
\times 10^{-5} \mathrm{~mol} \mathrm{~L}^{-1} \\
\end{array}$ & $\mathrm{k} \times 10^{4} \mathrm{~s}^{-1}$ & $\begin{array}{c}\text { Fast green } \times \\
10^{-5} \mathrm{~mol} \mathrm{~L}^{-1}\end{array}$ & $\mathrm{k} \times 10^{4} \mathrm{~s}^{-1}$ \\
\hline 1.78 & 2.02 & 1.0 & 3.32 \\
\hline 1.85 & 2.34 & 1.2 & 4.05 \\
\hline 1.92 & 2.78 & 1.3 & 4.84 \\
\hline 2.00 & 3.04 & 1.4 & 5.12 \\
\hline 2.08 & 3.56 & 1.5 & 4.69 \\
\hline 2.12 & 3.86 & 1.6 & 4.10 \\
\hline 2.22 & 3.47 & 1.7 & 3.45 \\
\hline 2.32 & 3.12 & 1.8 & 2.97 \\
\hline- & - & 1.9 & 2.65 \\
\hline
\end{tabular}

It was observed that rate of reaction increases with increase in the concentration of the dyes up to $1.40 \times 10^{-5}$ and $2.12 \times$ $10^{-5}$ for fast green and brilliant green, respectively. It may be due to the availability of more dye molecules for excitation and degradation, which increases the rate of reaction initially, but further increase in concentration leads to decrease in photocatalytic degradationof both the dyes. It may be due to the fact that increased dye concentration starts acting as a filter for the incident light and does not permit the desired light intensity to reach the semiconductor surface; hence decreasing the rate of photocatalytic degradation of dyes.

Effect of amount of semiconductor: Amount of semiconductor also affects the photo degradation of dyes. The results are reported in (Table-3).

It is observed from the results that rate of photodegradation increased initially with the amount of semiconductor up to 
TABLE-3

EFFECT OF AMOUNT OF SEMICONDUCTOR

\begin{tabular}{|c|c|c|c|}
\hline \multicolumn{2}{|c|}{$\begin{array}{l}\text { Brilliant green } \\
{[\text { Brilliant green }]=2.12 \times 10^{-5}} \\
\text { Dopant } \%=1.5 \% \\
\text { Light intensity }=50.0 \mathrm{mWcm}^{-2}\end{array}$} & \multicolumn{2}{|c|}{$\begin{array}{l}\text { Fast green } \\
{[\text { Fast green }]=1.40 \times 10^{-5}} \\
\text { Dopant } \%=2 \% \\
\text { Light intensity }=50.0 \mathrm{mWcm}^{-2}\end{array}$} \\
\hline $\begin{array}{c}\text { Doped } \\
\mathrm{CeCoO}_{3}(\mathrm{~g})\end{array}$ & $\mathrm{K} \times 10^{4} \mathrm{~s}^{-1}$ & $\begin{array}{c}\text { Doped } \\
\mathrm{CeCoO}_{3}(\mathrm{~g})\end{array}$ & $\mathrm{K} \times 10^{4} \mathrm{~s}^{-1}$ \\
\hline 0.02 & 3.86 & 0.02 & 4.32 \\
\hline 0.04 & 3.72 & 0.03 & 4.70 \\
\hline 0.06 & 3.43 & 0.04 & 5.12 \\
\hline 0.08 & 3.08 & 0.05 & 5.02 \\
\hline 0.10 & 2.92 & 0.06 & 4.91 \\
\hline 0.12 & 2.75 & 0.07 & 4.87 \\
\hline 0.14 & 2.70 & 0.08 & 4.82 \\
\hline- & - & 0.09 & 4.80 \\
\hline
\end{tabular}

amount $(0.04 \mathrm{~g}$ and $0.02 \mathrm{~g}$ ) for fast green and brilliant green respectively but after this amount, there is no increase in the exposed surface area of the photocatalyst. As with increase in amount of semiconductor, only thickness of the layer increases, but availability of active sites on catalyst surface and light penetration are reduced in the suspension.

Effect of \% of dopant: The effect of \% variation of dopant on both dyes was observed by taking different $\%$ variation of doped semiconductor. The results are reported in Table-4. It was observed that as $\%$ of dopant was increased, the rate constants were also increased. At $2 \%, 1.5 \%$ of dopant, the rate of reaction was optimum for fast green and brilliant green dyes respectively and after that rate of reaction was decreased. It may be due to the reason that freely active sites decreases after this dopant concentration and therefore, the rate of reaction started decreasing.

\begin{tabular}{|c|c|c|c|}
\hline \multicolumn{4}{|c|}{$\begin{array}{c}\text { TABLE-4 } \\
\text { EFFECT OF \% VARIATION OF DOPANT }\end{array}$} \\
\hline \multicolumn{2}{|c|}{$\begin{array}{l}\text { Brilliant green } \\
{[\text { Brilliant green }]=2.12 \times 10^{-5}} \\
\mathrm{pH}=9.0 \\
\text { Amount }=0.02 \mathrm{~g} \\
\text { Light intensity }=50.0 \mathrm{mWcm}^{-2}\end{array}$} & \multicolumn{2}{|c|}{$\begin{array}{l}\text { Fast green } \\
{[\text { Fast green }]=1.40 \times 10^{-5}} \\
\mathrm{pH}=8.5 \\
\text { Amount }=0.04 \mathrm{~g} \\
\text { Light intensity }=50.0 \mathrm{mWcm}^{-2}\end{array}$} \\
\hline$\%$ of Dopant & $\mathrm{k} \times 10^{4} \mathrm{~s}^{-1}$ & $\%$ of Dopant & $\mathrm{k} \times 10^{4} \mathrm{~s}^{-1}$ \\
\hline 0.5 & 3.55 & 0.5 & 4.85 \\
\hline 1.0 & 3.79 & 1.0 & 4.92 \\
\hline 1.5 & 3.86 & 1.5 & 5.02 \\
\hline 2.0 & 3.80 & 2.0 & 5.12 \\
\hline 2.5 & 3.75 & 2.5 & 5.10 \\
\hline
\end{tabular}

Effect of light intensity: To investigate the effect of light intensity on the rate of photocatalytic degradation of fast green and brilliant green, the distance between the light source and the exposed surface area was varied. The results are reported in Table-5.

The data indicate that photocatalytic degradation of both the dyes accelerated as the intensity of light increased, because an increase in the light intensity increases the number of photons striking per unit area of semiconductor surface per unit time. On further increasing the intensity of light above $50 \mathrm{~mW} / \mathrm{cm}^{2}$, there was decrease in the rate of reaction of both the dyes under considerations. This may be due to some side reactions or thermal reaction.

\begin{tabular}{|c|c|c|c|}
\hline \multicolumn{4}{|c|}{$\begin{array}{c}\text { TABLE-5 } \\
\text { EFFECT OF LIGHT INTENSITY }\end{array}$} \\
\hline \multicolumn{2}{|c|}{$\begin{array}{l}\text { Brilliant green } \\
{\left[\text { Brilliant green] }=2.12 \times 10^{-5}\right.} \\
\text { Dopant } \%=1.5 \% \\
\mathrm{pH}=9.0 \\
\text { Amount }=0.02 \mathrm{~g}\end{array}$} & \multicolumn{2}{|c|}{$\begin{array}{l}\text { Fast green } \\
{[\text { Fast green }]=1.40 \times 10^{-5}} \\
\text { Dopant } \%=2 \% \\
\mathrm{pH}=8.5 \\
\text { Amount }=0.04 \mathrm{~g}\end{array}$} \\
\hline $\begin{array}{l}\text { Light intensity } \\
\left.(\mathrm{mW} \mathrm{cm})^{-2}\right)\end{array}$ & $\mathrm{K} \times 10^{4} \mathrm{~s}^{-1}$ & $\begin{array}{l}\text { Light intensity } \\
\left.(\mathrm{mW} \mathrm{cm})^{-2}\right)\end{array}$ & $\mathrm{K} \times 10^{4} \mathrm{~s}^{-1}$ \\
\hline 10 & 3.02 & 10 & 4.06 \\
\hline 20 & 3.16 & 20 & 4.24 \\
\hline 30 & 3.38 & 30 & 4.55 \\
\hline 40 & 3.67 & 40 & 4.75 \\
\hline 50 & 3.86 & 50 & 5.12 \\
\hline 60 & 3.72 & 60 & 5.00 \\
\hline 70 & 3.64 & 70 & 4.85 \\
\hline
\end{tabular}

\section{Conclusion}

Photocatalytic activity of doped $\mathrm{CeCoO}_{3}$ catalyst showed enhanced photocatalytic activity with the dye fast green than brilliant green. This catalyst has potential to be used as photocatalyst for industrial dye removal. Its synthesis is very cost effective and it works well in visible light.

\section{REFERENCES}

1. S.K. Khetan and T.J. Collins, Chem. Rev., 107, 2319 (2007); https://doi.org/10.1021/cr020441w.

2. M. Ali and T.R. Sreekrishnan, Adv. Environ. Res., 5, 175 (2001); https://doi.org/10.1016/S1093-0191(00)00055-1.

3. E. Forgacs, T. Cserhati and G. Oros, Environ. Int.., 30, 953 (2004); doi.org/10.1016/j.envint.2004.02.001.

4. J. Tang, Z. Zou and J. Ye, Catal. Lett., 92, 53 (2004); https://doi.org/10.1023/B:CATL.0000011086.20412.aa.

5. J. Jose, J. Ameta, P.B. Punjabi, V.K. Sharma and S.C. Ameta, Bull. Catal. Soc. Ind., 6, 110 (2007).

6. V.R. Choudhary, K.C. Mondal, A.S. Mamman and U.A. Joshi, Catal. Lett., 100, 271 (2005); https://doi.org/10.1007/s10562-004-3467-0.

7. N.P. Mohabansi, V.B. Patil and N.A. Yenkie, Rasayan J. Chem., 4, 814 (2011).

8. R. Ullah and J. Dutta, J. Hazard. Mater, 156, 194 (2008); https://doi.org/10.1016/j.jhazmat.2007.12.033.

9. P. Banerjee, D. Das, P. Mitra, M. Sinha, S. Dey and S. Chakrabarti, J. Mater. Environ. Sci., 5, 1206 (2014).

10. P. Saharan, G.R. Chaudhary, S.K. Mehta and A. Umar, Nanosci. Nanotechnol. Lett., 8, 965 (2016); https://doi.org/10.1166/nnl.2016.2182.

11. J. Pooralhossini, M. Ghaedi, M.A. Zanjanchi and A. Asfaram, Ultrason. Sonochem., 37, 452 (2017); https://doi.org/10.1016/j.ultsonch.2017.01.038.

12. K.L. Ameta, N. Papnai and R. Ameta, J. Mater, Article ID 480107 (2014); https://doi.org/10.1155/2014/480107.

13. G. Yan, M. Zhang, J. Hou and J. Yang, Mater. Chem. Phys., 129, 553 (2011); https://doi.org/10.1016/j.matchemphys.2011.04.063.

14. S.K. Dawery, J. Eng. Sci. Technol., 8, 683 (2013).

15. D. Vaya and V.K. Sharma, J. Chem. Pharm. Res., 2, 269 (2010).

16. J. Tolia, M. Chakraborty and Z.V. Murthy, Int. J. Chem. Eng. Appl., 3, 136 (2012); https://doi.org/10.7763/IJCEA.2012.V3.174.

17. S. Ahmed, M.G. Rasul, W.N.Markns, R. Brown and M.A HA.

18. M.R. Mohammad and F.A. Choudhury, Chem. Eng. J., 27, 65 (2012). 